\title{
Exploiting the dividend month premium: evidence from Germany
}

\author{
Felix KreidI ${ }^{1}\left[\right.$ [ Hendrik Scholz ${ }^{1}$ (])
}

Revised: 5 March 2021 / Accepted: 23 March 2021 / Published online: 27 April 2021

(c) The Author(s) 2021

\begin{abstract}
Dividend payments are firm events on a recurring and predictable basis. High returns in the period between announcementdate and ex-dividend date are the main driver for the so-called dividend month premium, which are positive abnormal returns in months in which corporations are predicted to issue dividend payments. In our empirical analysis of the German stock market, we find a robust dividend month premium, which is particularly high for stocks with positive dividend surprise. Knowing the dates of dividend announcements and payments enable portfolio managers to exploit the dividend month premium. Also taking into account tracking error and transaction costs, we show that simple portfolio-enhancing strategies lead to highly significant abnormal returns.
\end{abstract}

Keywords Dividends · Dividend month premium · Dividend surprise $\cdot$ Cumulative abnormal returns · Outperformance Exploitation · Portfolio management

\section{Introduction}

Dividend payments are recurring firm events that are clearly predictable. Empirical evidence shows that these events tend to be associated with large positive returns (Hartzmark and Solomon 2018). Hartzmark and Solomon (2013) find positive abnormal returns for US stocks in months of predicted dividend payments, the so-called dividend month premium. Significant and positive abnormal returns in the interim period between announcement-date and ex-dividend date (in the following ex-date) are the main driver for the dividend month premium. This is in line with Lakonishok and Vermaelen (1986), who find abnormal returns for the five days prior to the ex-date. The dividend month premium is most consistent with the price pressure from dividend-seeking investors. Potential explanations for investors' demand for dividends include catering reasons (see, e.g., Baker and Wurgler 2004) or because investors do not consider the fall in stock prices from cum-dividend price to ex-dividend price (Hartzmark and Solomon 2019). Another reason for the dividend month premium could be mutual funds investing in

Felix Kreidl

felix.kreidl@fau.de

1 Chair of Finance and Banking, Friedrich-AlexanderUniversität Erlangen-Nürnberg (FAU), Lange Gasse 20, 90403 Nürnberg, Germany dividend-paying stocks in advance of ex-dates to increase their dividend yield (Harris et al. 2015).

Our paper contributes to the literature in various ways. With our analysis, we provide a comprehensive study of the dividend month premium in the German stock market. Based on monthly stock portfolios, Ainsworth and Nicholson (2015) confirm a dividend month premium for Germany, but do not provide a detailed analysis of the interim period. In our event study, we analyse daily returns of investible German stocks around announcement-dates and ex-dates. Taking dividend surprises into account, we also provide an even more detailed study of the dividend month premium in Germany and extend the analysis of Hartzmark and Solomon (2013). Finally, we discuss the practical relevance of the dividend month premium in portfolio management. In doing so, we study the profitability of beta-neutral investment strategies extending a basic market portfolio with additional investments in dividend-paying stocks.

The result of our event study is robust and shows a significant and positive cumulative abnormal return of $1.79 \%$ over the 45 days prior to the ex-date. This provides evidence for a dividend month premium in Germany. Our findings are in line with Ainsworth and Nicholson (2015), who find positive abnormal returns for German stocks in months when they are predicted to issue dividend payments. We further indicate that (i) post-announcement drifts are especially strong for stocks with positive dividend surprise and 
(ii) earnings announcements do not systematically affect our results. These results augment the study by Andres et al. (2013), providing evidence for price reactions to dividend announcements of German stocks. They find that stocks with positive dividend surprise, controlled for earnings announcements, show significantly positive abnormal returns, varying between 1.58 and $2.24 \%$, close to the announcement-date.

Further, we discuss the practical relevance of the dividend month premium in portfolio management. The predictable date of dividend payments enables portfolio managers to exploit the dividend month premium. We show that simple portfolio-enhancing strategies lead to significant abnormal returns along with reasonable tracking error and transaction costs. To exploit the dividend month premium, we apply beta-neutral investment strategies, extending a basic market portfolio with additional investments in dividend-paying stocks. The additional investments are zero-invest portfolios with a market beta of zero. For our sample period from April 2003 to December 2017, the beta-neutral strategies show 1-factor alphas between 0.13 and $0.47 \%$ per month. The tracking error varies between 0.45 and $1.61 \%$. Oneway break-even transaction costs between 0.30 and $1.76 \%$ emphasize the feasibility of our beta-neutral strategies. In additional analyses, our exploitation of the dividend month premium leads to similar results, even if we only consider the period after the publication of Hartzmark and Solomon (2013).

Our paper proceeds as follows. Section 2 describes the data. Section 3 develops the empirical methodology for the event study and presents the empirical results. Section 4 describes our beta-neutral strategies to exploit the dividend month premium and shows the performance and risk of the strategies. Finally, Section 5 concludes.

\section{Data and summary statistics}

We analyse dividend-paying stocks that are current constituents of the German HDAX index between March 2003 and December 2017. The HDAX has existed since March 24, 2003 and contains the 110 largest stocks with regard to their free-float market capitalization. It is a composite index that includes the large-cap index DAX 30, the mid-cap index MDAX, as well as the technology index TecDAX, and covers more than $90 \%$ of the total market capitalization of all German prime standard stocks.

Refinitiv EIKON is our main data source. The sample variables are stated in euros. We obtain information on adjusted dividend payments, announcement-dates and exdates. We generally exclude special dividends and capital bonuses, with the exception of special payments coinciding with the regular dividend payment. Further, we use total returns, free-float market capitalizations (market
Table 1 Summary statistics

\begin{tabular}{ll}
\hline & HDAX \\
\hline \# Months & 178 \\
\# Constituents & 219 \\
\# Dividend payments & 1337 \\
Dividend per stock (EUR) & \\
Mean & 1.26 \\
Median & 0.90 \\
Dividend yield (\%) & \\
Mean & 2.73 \\
Median & 2.14 \\
Market capitalization (Mio. EUR) & \\
Mean & 10,892 \\
Median & 3475 \\
\hline
\end{tabular}

This table provides summary statistics of our data sample. It covers all dividend-paying constituents of the German HDAX index between March 2003 and December 2017. Special dividends and capital bonuses are generally excluded, with the exception of special payments coinciding with the yearly common dividend payment. Data source: Refinitiv EIKON

capitalizations), dividend yields (DY), earnings announcements for the fourth fiscal quarter as well as announcementdates, mean I/B/E/S_estimates for dividend payments and earnings announcements, and the EONIA interest rate on a daily basis. In the context of performance measurement, we use the 1-month-EURIBOR from Deutsche Bundesbank as a proxy for the monthly risk-free interest rate and information on the German 4-factor model from the AQR data library. ${ }^{1}$

Table 1 provides summary statistics of our data sample. The index composition changes over time, resulting in 219 individual stocks with a total of 1337 dividend payments. German corporations generally pay dividends on a yearly basis. The mean dividend per stock is 1.26 euros, which corresponds to a mean DY of $2.73 \%$. The mean market capitalization of a corporation is 10,892 million euros.

Figure 1 illustrates the distribution of dividend payments between March 2003 and December 2017. The left graph reports the number of dividend payments over time, the right graph shows the average distribution of dividend payments within a year. We see a positive trend over the years with 73 dividend payments from March 2003 to December 2003 and 99 dividend payments in 2017. Within a year, dividend payments of German stocks are especially clustered in the months of April, May and June.

\footnotetext{
${ }^{1}$ Since these German factor returns are calculated in US dollars, we converted them into euros following Glück et al. (2021).
} 


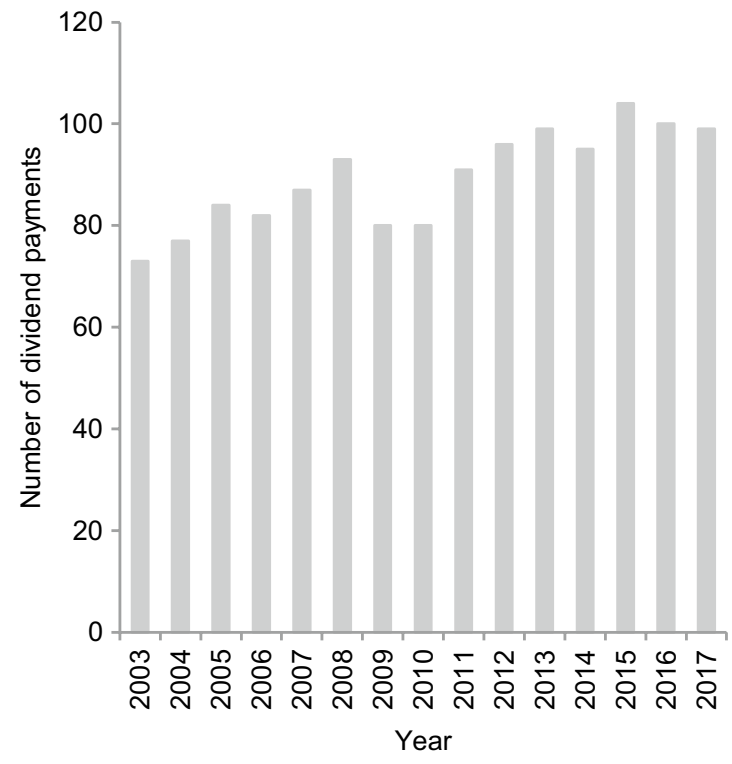

Fig. 1 Dividend payment distribution. This figure illustrates the distribution of dividend payments between March 2003 and December 2017. The left graph reports the dividend payments over time, the

\section{Event study}

\section{Methodology}

We calculate mean (cumulative) abnormal returns around ex-dates to analyse the dividend month premium in Germany. Our methodology is based on MacKinlay (1997) and uses a market model specification with a 150-day estimation window. For each stock $i$, we regress daily total returns on daily HDAX total returns over the 150 days to estimate $\hat{\alpha}_{i}$ and $\hat{\beta}_{\mathrm{i}}{ }^{2}$ For each day $\tau$ in the event window, the expected return of a stock $i, E\left[R_{i, \tau}\right]$, is calculated as follows:

$E\left[R_{i, \tau}\right]=\hat{\alpha}_{i}+\hat{\beta}_{i} R_{m, \tau}$,

where $R_{m, \tau}$ is the realized market total return for the respective day $\tau$. Our event window covers 45 days before and 45 days after an ex-date to get a holistic understanding of the data. It starts with the consecutive day after the estimation window. We also analyse various sub periods within the event window.

The abnormal return of a stock $i, \mathrm{AR}_{i, \tau}$, is the stock $i$ 's realized return, $R_{i, \tau}$, minus the respective expected return following equation (2):

\footnotetext{
${ }^{2}$ For robustness, we (i) apply a 200-day estimation window and (ii) estimate three market betas (lagged, matching and leading) and eventually aggregate those to get a consistent $\hat{\beta}$ for each stock (Dimson 1979). The results remain statistically and economically similar. Results are available upon request.
}

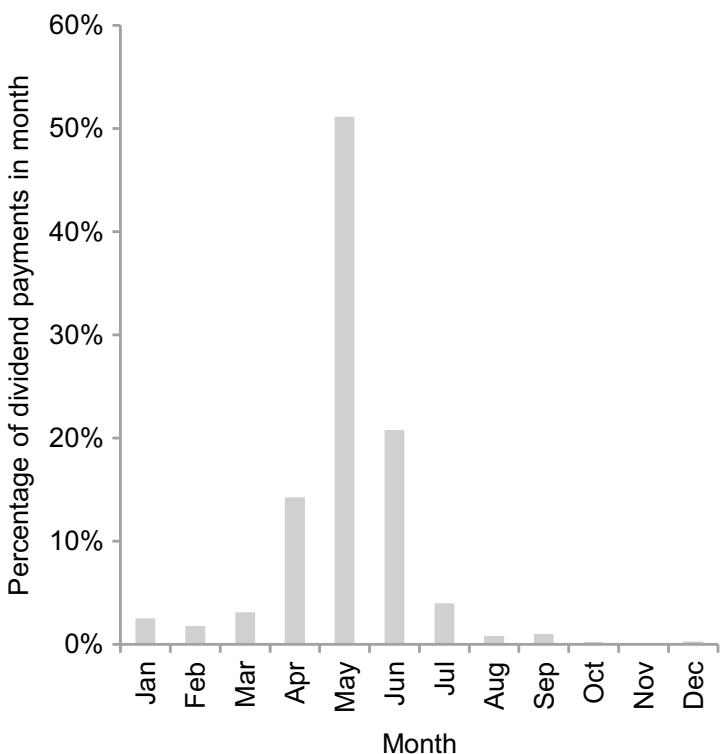

right graph shows the average distribution of dividend payments within a year. The data sample covers 1337 dividend payments. Data source: Refinitiv EIKON.

$\mathrm{AR}_{i, \tau}=R_{i, \tau}-\left(\hat{\alpha}_{i}+\hat{\beta}_{i} R_{m, \tau}\right)$

We calculate the mean abnormal return for day $\tau, \mathrm{AR}_{P, \tau}$, over all $N$ stocks as follows:

$\mathrm{AR}_{P, \tau}=\frac{1}{N} \sum_{i=1}^{N} \mathrm{AR}_{i, \tau}$

Further, we calculate the cumulative abnormal return for each stock $i, \mathrm{CAR}_{i,\left[\tau_{0}, \tau_{t}\right]}$, and eventually determine the mean cumulative abnormal return, $\mathrm{CAR}_{P,\left[\tau_{0}, \tau_{t}\right]}$, over all $N$ stocks according to equation (4).

$\operatorname{CAR}_{P,\left[\tau_{0}, \tau_{t}\right]}=\frac{1}{N} \sum_{i=1}^{N} \operatorname{CAR}_{i,\left[\tau_{0}, \tau_{t}\right]}=\frac{1}{N} \sum_{i=1}^{N} \sum_{\tau=\tau_{0}}^{\tau_{t}} \operatorname{AR}_{i, \tau}$

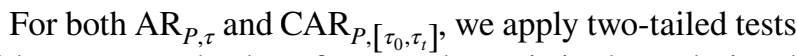
with an expected value of zero and $t$-statistics by Kolari and Pynnönen (2010) to account for possible event-induced volatility and cross-sectional correlation.

\section{Abnormal returns around ex-dates and announcement-dates}

Figure 2 presents the empirical results of our event study for Germany. The left graph shows the daily mean abnormal returns $\left(\mathrm{AR}_{P, \tau}\right)$ for our event window around the exdate. Bars in black have a $t$-statistic that is significant at the $10 \%$ level, while gray bars are not significant at this level. During the 45 days prior to the ex-date, days with positive 


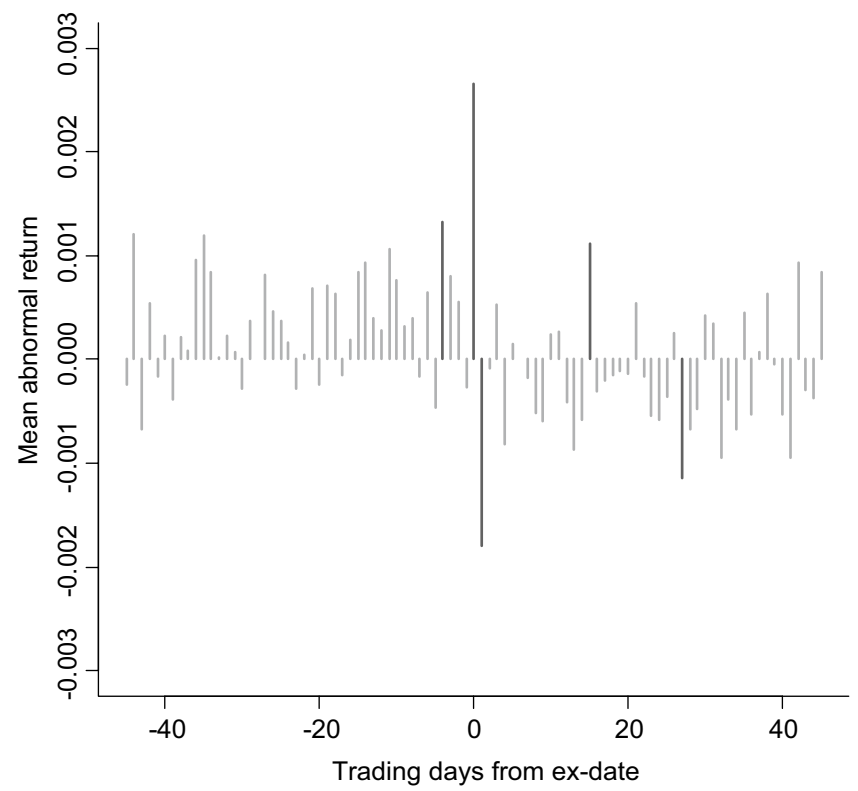

Fig. 2 Mean abnormal returns and mean cumulative abnormal return around ex-dates. The left graph shows daily mean abnormal returns for dividend-paying stocks for the days $[-45,45]$ relative to the exdate. The abnormal returns are based on a market model specification with a 150-day estimation window. Bars in black have a $t$-statistic that

$\mathrm{AR}_{P, \tau}$ outweigh days with negative mean abnormal returns, whereas negative $\mathrm{AR}_{P, \tau}$ dominate the period after the exdate. The significant and positive mean abnormal return for German stocks at the ex-date is largely equalized on the following day. This is in line with the findings by Haesner and Schanz (2013).

The right graph presents the mean cumulative abnormal return $\left(\mathrm{CAR}_{P,\left[\tau_{0}, \tau_{t}\right]}\right)$. Over the days $[-45,0]$ relative to the ex-date, the $\mathrm{CAR}_{P}$ equals $1.79 \%$ ( $t$-statistic of 2.92 ) and is highly significant. It reveals a systematic pattern of an increasing mean cumulative abnormal return prior to the exdate. The significant and positive mean cumulative abnormal return before the ex-date, however, is partially eliminated within the weeks following the ex-date. This is consistent with the findings by Hartzmark and Solomon (2013) for US stocks.

Germany applied two different tax systems during our sample period from March 2003 to December 2017. Additional analyses of the half-income system (up to December 2008) and the flat-tax system (from 2009 onwards) produce similar results. Over the days $[-45,0]$ relative to the exdate, both $\mathrm{CAR}_{P}$ equal $1.55 \%$ ( $t$-statistic of 1.71 ) and $1.93 \%$ ( $t$-statistic of 2.33), respectively.

In our sample, the average distance between announcement-date and ex-date is 49 days. Thus potential announcement-date effects, as discussed in Andres et al. (2013), may affect our results. In the following, we sort our sample by dividend surprises. To this end, we compare the actual

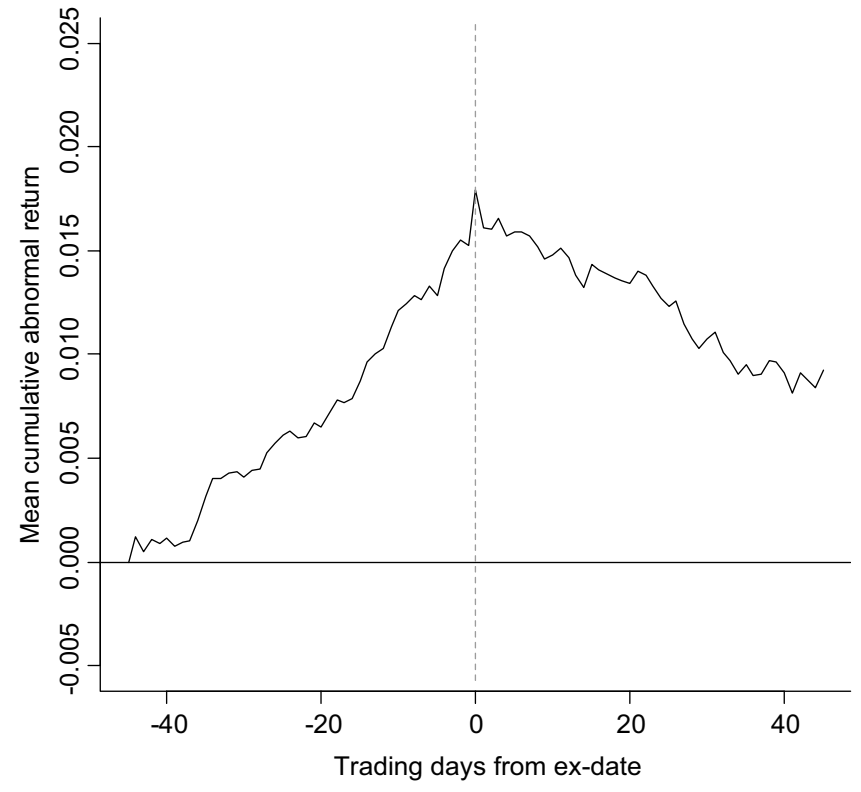

is significant at the $10 \%$ level, bars in gray are not significant at this level. The right graph presents the mean cumulative abnormal return. We apply $t$-statistics by Kolari and Pynnönen (2010). The data sample covers 1337 dividend payments between March 2003 and December 2017. Data source: Refinitiv EIKON

dividend payment with the mean $\mathrm{I} / \mathrm{B} / \mathrm{E} / \mathrm{S}$ _estimate for the respective dividend payment available one day in advance of the announcement-date. It is positive (negative) news if the difference, in relation to the $\mathrm{I} / \mathrm{B} / \mathrm{E} / \mathrm{S} \_$estimate, is larger (smaller) than 5\% (-5\%). This results in 367 positive news dividends, 524 no news dividends and 361 negative news dividends. $^{3}$

The left graph in Figure 3 presents the $\mathrm{CAR}_{P,\left[\tau_{0}, \tau_{t}\right]}$ around announcement-dates for our three sub samples. Over the ten days following the announcement-date, stocks with positive news show an increase in the $\mathrm{CAR}_{P}$ of about $1 \%$, and stocks with negative news display a decrease by circa $1 \%$. During the subsequent weeks, both mean cumulative abnormal returns show a positive drift. The no news sub sample does not show any significant variation.

The right graph in Figure 3 illustrates the $\mathrm{CAR}_{P,\left[\tau_{0}, \tau_{t}\right]}$ for our sub samples around ex-dates. Over the days $[-45,0]$ relative to the ex-date, the $\mathrm{CAR}_{P}$ is largest for positive news stocks with $2.39 \%$ ( $t$-statistic of 1.85 ). The no news stocks and negative news stocks show economically comparable results with a $\mathrm{CAR}_{P}$ of $1.67 \%$ ( $t$-statistic of 1.85 ) and a $\mathrm{CAR}_{P}$ of $1.35 \%$ ( $t$-statistic of 0.35 ), respectively.

Table 2 summarizes our findings and provides the mean cumulative abnormal return for the full sample (all) as well

\footnotetext{
$\overline{3}$ We lose 85 observations due to data unavailability. Figure 5 in the appendix illustrates the distribution over time.
} 


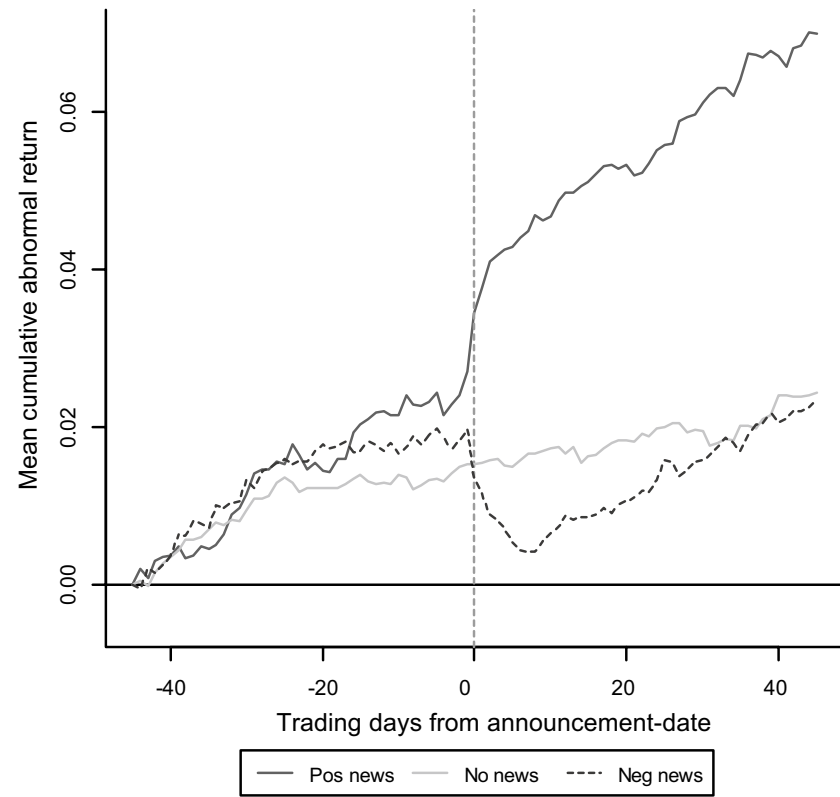

Fig. 3 Mean cumulative abnormal returns of dividend surprise sub samples. The left graph presents the mean cumulative abnormal return for our three sub samples with stocks having dividends with positive news (solid black line), no news (solid gray line) and negative news (dashed black line) around announcement-dates. The difference between a corporation's actual dividend announcement and the mean I/B/E/S_estimate for the respective dividend payment defines the dividend surprise. We use the mean I/B/E/S_estimate available

Table 2 Mean cumulative abnormal returns

\begin{tabular}{lllll}
\hline & $\begin{array}{l}\mathrm{CAR}_{P} \\
\text { Announce- } \\
\text { ment-date }\end{array}$ & & Ex-date \\
\hline All & {$[1,22]$} & {$[1,45]$} & {$[-22,0]$} & {$[-45,0]$} \\
Positive news & 0.0055 & $0.0153^{* *}$ & $0.0119 * * *$ & $0.0179 * * *$ \\
No news & $0.0179 * *$ & $0.0355^{* * *}$ & 0.0126 & $0.0239 *$ \\
Negative news & -0.0016 & 0.0090 & $0.0107 * *$ & $0.0167 *$ \\
\hline
\end{tabular}

This table shows the mean cumulative abnormal return $\left(\mathrm{CAR}_{P,\left[\tau_{0}, \tau_{t}\right) \text { for }}\right.$ the full sample (all) and three sub samples with stocks having dividends with positive news, no news and negative news. The $C A R_{P}$ is presented for event windows after announcement-dates and prior to ex-dates. The difference between a corporation's actual dividend announcement and the mean I/B/E/S_estimate for the respective dividend payment defines the dividend surprise. We use the mean I/B/E/S_estimate available one day in advance of the announcement-date. It is positive (negative) news if the difference is larger (smaller) than 5\% (-5\%). The abnormal returns are based on a market model specification with a 150-day estimation window. The data sample covers 1337 dividend payments between March 2003 and December 2017. We lose 85 observations for our sub samples due to data unavailability. We apply $t$-statistics by Kolari and Pynnönen (2010). *, ** and *** indicate statistical significance at the $10 \%, 5 \%$ and $1 \%$ level, respectively. Data source: Refinitiv EIKON.

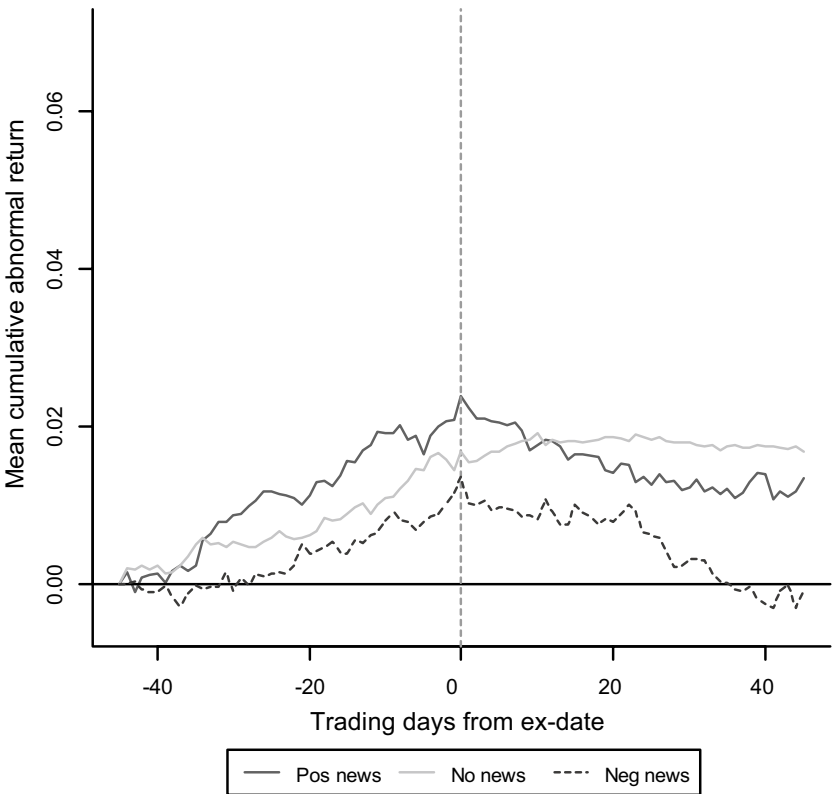

one day in advance of the announcement-date. It is positive (negative) news if the difference is larger (smaller) than $5 \%(-5 \%)$. The abnormal returns are based on a market model specification with a 150-day estimation window. The right graph illustrates the mean cumulative abnormal return around ex-dates. The data sample covers 1252 dividend payments between March 2003 and December 2017. Data source: Refinitiv EIKON

as our three sub samples sorted by dividend surprises around announcement-dates and ex-dates. We show results for sub periods covering the days $[1,22]$ and $[1,45]$ relative to the announcement-date as well as $[-22,0]$ and $[-45,0]$ relative to the ex-date. Positive news stocks show a significant and positive $\mathrm{CAR}_{P}$ after announcement-dates and in advance of ex-dates. The $\mathrm{CAR}_{P}$ varies between 1.26 and $3.55 \%$. Negative news stocks show a statistically insignificant $\mathrm{CAR}_{P}$ over all specifications. In advance of ex-dates, the high variation in the abnormal returns of stocks with negative news lead to an economically high, but statistically insignificant, $\mathrm{CAR}_{P}$. The $\mathrm{CAR}_{P}$ is $1.22 \%$ over the days $[-22,0]$ and is $1.35 \%$ over the days $[-45,0]$ around to the ex-date. Overall, our empirical analysis suggests that post-announcement drifts are particularly strong for German stocks with positive dividend surprise.

\section{Alternative explanations for the dividend month premium}

\section{Earnings surprises}

There is the possibility that the drift after announcements of positive dividend surprises is also associated with (positive) earnings surprises. Among others, Battalio and Mendenhall (2005) and Andres et al. (2013) provide evidence of 
earnings-announcement effects, which may coincide with our analysis of dividend announcement effects. Therefore, we extend our study and include a panel regression analysis to examine the CARs in greater detail. This allows us to show that (i) dividend surprises explain variation in the CARs, and (ii) there is no significant linear relationship between earnings surprises and our CAR.

We use the $\mathrm{CAR}_{i,[-45,0]}$ over the 45 days prior to the exdate for every dividend event $i$ and regress these CARs on different sets of explanatory variables. In model (1), we use dividend surprise (DS) as explanatory variable, and we further consider earnings surprise (ES) ${ }^{4}$ in model (2). Thus, we can study the relationship between our CARs and DS as well as ES in greater detail. In model (3), we follow the literature (see, e.g., Andres et al. 2013; Flammer 2013; Krueger 2015) taking into account the additional control variables leverage (Lev), return on assets (RoA), the natural logarithm of free-float market capitalization ( $\operatorname{Ln}(\mathrm{Cap}))$, price-to-book ratio (PtB), the natural logarithm of the number of analysts ( $\operatorname{Ln}($ Analysts)), as well as dividend yield (DY). For all three models, we apply panel regressions with random effects ${ }^{5}$.

Table 3 shows our regression results. We find a positive and robust linear relationship between the $\mathrm{CAR}_{i,[-45,0]}$ and dividend surprise. The point estimates are positive and highly significant for all three models varying between $1.21 \%$ (model (1)) and 1.44\% (model (3)). In models (2) and (3), the estimates for the earnings surprise are negative and insignificant, also when controlling for additional control variables. This outcome suggests that positive dividend surprises ceteris paribus enhance the $\mathrm{CAR}_{i,[-45,0]}$ prior to the ex-date and that there is no significant linear relationship between $\mathrm{CAR}_{i,[-45,0]}$ and earnings surprise. A plausible explanation for the positive relationship between the $C A R_{i,[-45,0]}$ and dividend surprise is that the management's dividend signaling reflects a long-term perspective of a company's future cash flows. Investors may see this as a reliable signal. As shown by the left graph in Figure 3 discussed above, the abnormal returns regarding dividend announcements for both positive and negative news are most prominent during the five trading days from the announcement. This illustrates that investors systematically trade to dividend news which, eventually, lead to a significant linear relationship between $\mathrm{CAR}_{i,[-45,0]}$ and dividend surprise. Thus, the dividend month premium of German stocks, as measured

\footnotetext{
${ }^{4}$ We calculate earnings surprises in the similar way to dividend surprises. The difference between a corporation's actual earnings announcement (for Q4) and the mean I/B/E/S_estimate for the respective earnings amount, in relation to the $\mathrm{I} / \mathrm{B} / \mathrm{E} / \mathrm{S}$ _estimate, defines the earnings surprise. We use the mean I/B/E/S_estimate available one day in advance of the announcement date.

${ }^{5}$ Hausman tests cannot reject the null, thus the random-effects estimators should be consistent and efficient.
}

Table 3 Regression of CARs on dividend surprise, earnings surprise and control variables

\begin{tabular}{|c|c|c|c|}
\hline & (1) & (2) & (3) \\
\hline \multirow[t]{2}{*}{$\beta^{\mathrm{DS}}$} & $0.0121 * * *$ & $0.0124 * * *$ & $0.0144 * * *$ \\
\hline & $(0.0046)$ & $(0.0042)$ & $(0.0025)$ \\
\hline \multirow[t]{2}{*}{$\beta^{\mathrm{ES}}$} & & -0.0056 & -0.0038 \\
\hline & & $(0.0043)$ & $(0.0038)$ \\
\hline \multirow[t]{2}{*}{$\beta^{\mathrm{Lev}}$} & & & $-0.0018 * * *$ \\
\hline & & & $(0.0005)$ \\
\hline \multirow[t]{2}{*}{$\beta^{\mathrm{RoA}}$} & & & $0.0879 * *$ \\
\hline & & & $(0.0380)$ \\
\hline \multirow[t]{2}{*}{$\beta^{\operatorname{Ln}(\text { Cap })}$} & & & $-0.0170 * * *$ \\
\hline & & & $(0.0060)$ \\
\hline \multirow[t]{2}{*}{$\beta^{\mathrm{PtB}}$} & & & $-0.0091 * * *$ \\
\hline & & & $(0.0023)$ \\
\hline \multirow[t]{2}{*}{$\beta^{\text {Ln(Analysts) }}$} & & & $0.0293 * *$ \\
\hline & & & (0.0139) \\
\hline \multirow[t]{2}{*}{$\beta^{\mathrm{DY}}$} & & & $-0.0068 * *$ \\
\hline & & & $(0.0034)$ \\
\hline \multirow[t]{2}{*}{$\gamma$} & $0.0115^{* *}$ & $0.0111 * *$ & $0.1007 * * *$ \\
\hline & $(0.0049)$ & $(0.0050)$ & $(0.0354)$ \\
\hline $\operatorname{Adj} . R^{2}$ & 0.0060 & 0.0071 & 0.0626 \\
\hline$N$ & 1002 & 1002 & 1002 \\
\hline Model & Panel RE & Panel RE & Panel RE \\
\hline
\end{tabular}

This table provides the results for the panel regression following equation $\mathrm{CAR}_{i,[-45,0]}=\gamma_{i}+\beta^{\mathrm{DS}} \mathrm{DS}+\beta^{\mathrm{ES}} \mathrm{ES}+\beta^{x} X_{+} \varepsilon_{i}$. The dependent variable is a stock's cumulative abnormal return, $C A R_{i,[-45,0]}$, over the 45 days prior to its ex-date. The abnormal returns are based on a market model specification with a 150-day estimation window. We regress the $C A R_{i,[-45,0]}$ on the variables dividend surprise (DS) and earnings surprise (ES), which are the differences between a corporation's actual announcements and the mean $\mathrm{I} / \mathrm{B} / \mathrm{E} / \mathrm{S}$ _estimates for the respective dividend or earnings amounts, in relation to the $\mathrm{I} / \mathrm{B} /$ E/S_estimates. $X$ is a vector of control variables. Leverage (Lev) is defined as total debt over total book equity. Return on assets (RoA) is calculated as a firm's EBIT over total assets. Further, we use the natural logarithm of the free-float market capitalization $(\operatorname{Ln}(\mathrm{Cap}))$ of day $t$-45. The price-to-book ratio $(\mathrm{PtB})$ is defined as the stock price, of day $t-45$, over the book equity per stock. Additional variables are the natural logarithm of the number of analysts $(\operatorname{Ln}($ Analysts $))$ covering the firm as of day $t$-1 relative to the earnings-announcement date as well as the dividend yield (DY). The data sample covers dividend payments between March 2003 and December 2017. Due to missing values, not all dividend payments in the data are included. Regression coefficients result from panel regressions with random effects (RE), and we present cluster-robust standard errors in parentheses. *,**, and $* * *$ indicate statistical significance at the $10 \%, 5 \%$ and $1 \%$ level, respectively. Data source: Refinitiv EIKON

by $\mathrm{CAR}_{i,[-45,0]}$, is particularly high for stocks with positive dividend news and vice versa.

Overall, we can conclude that earnings surprises do not enhance the $\mathrm{CAR}_{i,[-45,0]}$ prior to ex-dates. Moreover, the German dividend month premium is higher for stocks with 
positive dividend news due to a respective post-announcement drift.

\section{Cum/cum trading and cum/ex trading}

Recently, so-called cum/cum trading and cum/ex trading received a lot public attention in Germany. Cum/cum trading aims to reduce the withholding-tax burden on dividend payments, especially for foreign investors. Cum/ex trades are specifically designed to obtain illegitimate tax refunds due to short trading around ex-dates (see, e.g., Spengel 2016). In the following, we discuss in detail that both cum/cum trading as well as cum/ex trading do not affect our analysis of the German dividend month premium.

As outlined by Spengel (2016), cum/cum trading was supposed to be predominantly based on stocks lending. Since this implies no sales and purchases of stocks and, thus, no impact on stock prices, cum/cum trading most likely does not bias our results. The effects of cum/ex trading, on the other hand, require a discussion of greater detail.

In January 2012, there was a change in the legislation preventing illegitimate tax refunds due to cum/ex trading in Germany (Spengel 2016; Buettner et al. 2020). This means that cum/ex trading may had an effect on our results in the years from 2003 to 2011. Buettner et al. (2020) carefully illustrate technical details of a cum/ex trade, which requires a short sale on one of the two days prior to the ex-date and a purchase of the respective stock on the ex-date itself. They also reveal a cum/ex trade's collusive nature in their theoretical analysis, which implies arranged trading by at least cum/ ex seller and cum/ex buyer. Hence, it is likely that cum/ex trades are not executed via the anonymous order book, but rather via bilateral trading at market-compliant conditions. Furthermore, since collusion does not alter the demand-supply ratio of a stock, cum/ex trades lead to abnormal volumes but not to abnormal returns on the respective days around a stock's ex-date. Consistent with their collusion hypothesis, Buettner et al. (2020) do find striking patterns in the trading volumes around ex-dates of German stocks, but no abnormal returns. As a result, we can conclude that cum/ex trading should not affect our analysis of the German dividend month premium. ${ }^{6}$

\footnotetext{
${ }^{6}$ In addition to our theoretical discussion, we further provide empirical evidence that cum/ex trading does not systematically affect ARs in our analysis. Since a cum/ex trade (without collusion) comes with a short sale on one of the two days prior to the ex-date, followed by a purchase of the respective stock on the ex-date, we examine these very days in particular. We analyse the relevant sub period covering all trading days between March 2003 and December 2011. For all three days, we find insignificant and positive ARs. This implies that cum/ex trading does not systematically affect our analysis of ARs in the years between 2003 and 2011. Our result is in line with the collusion hypothesis as well as the findings by Buettner et al. (2020). Results are available upon request.
}

Overall, cum/cum as well as cum/ex trading took place during our analysis of the German stock market. However, these trading strategies do not significantly affect prices of German stocks. Firstly, cum/cum trading is predominantly based on stocks lending that implies no impact on stock prices. Secondly, cum/ex trading does not affect stock prices in our analysis due to its collusive nature. Thus, cum/cum trading and cum/ex trading should not significantly affect the dividend month premium in Germany.

\section{Exploitation of the dividend month premium}

\section{Methodology}

This section discusses the implementation of the dividend month premium in a tangible investment strategy. The recurring, predictable date of dividend payments enables portfolio managers to easily exploit the dividend month premium. We model simple portfolio-enhancing strategies with a focus on the interim period between announcement-date and ex-date. Since mean abnormal returns on the announcement-date are not fully exploitable, we initiate our strategy at the end of the announcement-date to avoid a biased performance of the portfolios.

The basic portfolio of our beta-neutral strategies results from an investment in the HDAX index (in the following "market"). Based on this market investment, we additionally invest in each dividend-paying stock at the end of the announcement-date, liquidating this additional single-stock investment at the end of the ex-date. On the day of the single-stock investment, our beta-neutral strategies keep the systematic risk of the underlying market investment unchanged at one. In this way, we take into account portfolio managers' potential requirements regarding the systematic risk of their portfolios. Assuming an investment of 1000 in a stock showing a market exposure (market beta) of 1.3 , for instance, we additionally go short in the market by 1300 and invest the residual 300 in the EONIA (short-term rate). ${ }^{7}$ Hence, at the end of the announcement-date, our betaneutral strategies add a zero-invest portfolio with a market beta of zero to the basic market investment.

In terms of the additional investment in each stock, we apply an equal weight (in the following, ew) approach and a value weight (vw) approach. At the end of the announcement-date of an additional single-stock investment, every stock gets the same additional relative weight. With the ew approach, we choose a weight of 3/110 of the portfolio value at the end of the announcement-date. With the

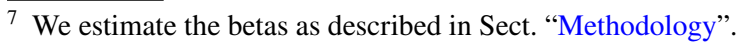


vw approach, every stock gets a relative weight by dividing a stock's triple market capitalization by the total market capitalization of the current constituents of the sample at the end of the announcement-date. The applied weights are arbitrary depending on investors' portfolio needs and trading costs.

The holding period of each additional investment in a dividend-paying stock starts at the end of the announcementdate and ends with the liquidation at the end of the ex-date. The average holding period is 48 days. The potential gain will be reallocated to the basic market investment at the end of the ex-date. The underlying holding period exploits the maximum length. Of course, shorter holding periods are applicable.

To evaluate the performance of our strategies, we apply the mean return, Sharpe Ratio (Sharpe 1994) and information ratio (Treynor and Black 1973), which are common measures in portfolio management. The tracking error of the beta-neutral strategy is calculated following Roll (1992) as the standard deviation of the benchmark-adjusted return, defined as the monthly portfolio return minus the monthly HDAX return. Moreover, we apply a 1-factor model (Jensen 1968) and a 4-factor model (Carhart 1997) OLS estimation as stated in Eqs. (5) and (6):

$R_{p, t}-R_{f, t}=\alpha_{p}^{1 F}+\beta_{p}^{\mathrm{HDAX}}\left(R_{\mathrm{HDAX}, t}-R_{f, t}\right)+\varepsilon_{p, t}$

$$
\begin{gathered}
R_{p, t}-R_{f, t}=\alpha_{p}^{1 F}+\theta_{p}^{1 F} D_{t}^{Q 2}+\beta_{p}^{\mathrm{HDAX}}\left(R_{\mathrm{HDAX}, t}-R_{f, t}\right) \\
+\omega_{p}^{\mathrm{HDAX}} D_{t}^{Q 2}\left(R_{\mathrm{HDAX}, t}-R_{f, t}\right)+\varepsilon_{p, t} \\
R_{p, t}-R_{f, t}=\alpha_{p}^{4 F}+\theta_{p}^{4 F} D_{t}^{Q 2}+\beta_{p}^{\mathrm{Mkt}}\left(\mathrm{Mkt}_{t}-R_{f, t}\right)+\omega_{p}^{\mathrm{Mkt}} D_{t}^{Q 2}\left(\mathrm{Mkt}_{t}-R_{f, t}\right) \\
+\beta_{p}^{\mathrm{SMB}} \mathrm{SMB}_{t}+\beta_{p}^{\mathrm{HML}} \mathrm{HML}_{t}+\beta_{p}^{\mathrm{WML}} \mathrm{WML}_{t}+\varepsilon_{p, t}
\end{gathered}
$$

Further, we show the yearly average turnover (turnover) for our strategy. As for the daily turnover, we calculate the sum of all liquidated single-stock investments at day $t$ divided by the portfolio value of the respective day $t$. We aggregate the daily turnovers over a year and calculate the yearly average over the sample period.

Finally, following Grundy and Martin (2001), we estimate the level of transaction costs that removes the statistical significance of the 1 -factor alpha at the $10 \%$ level. We state the respective one-way break-even transaction costs (BETCs) ${ }^{10}$ in the following.

\section{Performance and risk of beta-neutral investment strategies}

This section presents the performance and risk measures of our beta-neutral strategies to exploit the dividend month premium.

$R_{p, t}-R_{f, t}=\alpha_{p}^{4 F}+\beta_{p}^{\mathrm{Mkt}}\left(\mathrm{Mkt}_{t}-R_{f, t}\right)+\beta_{p}^{\mathrm{SMB}} \mathrm{SMB}_{t}+\beta_{p}^{\mathrm{HML}} \mathrm{HML}_{t}+\beta_{p}^{\mathrm{WML}} \mathrm{WML}_{t}+\varepsilon_{p, t}$

In Eq. (5), we regress monthly portfolio excess returns on monthly German HDAX excess returns. This is an obvious choice, since our investment strategy exploiting the dividend month premium is based on constituents of the HDAX. ${ }^{8}$ In Eq. (6), we use the German factors market, size (SMB), value (HML) and momentum (WML) from the AQR data library as explanatory variables. Thus, as common in the literature, all four factors are based on the identical data set.

More than 80 percent of ex-dates in our sample occur in the second quarter of a year. To take the cluster of singlestock investments into account, we further interact the models in Eqs. (5) and (6) by a binary variable $D^{Q 2}$ that takes the value one in the respective months April, May, June and zero otherwise. We include interaction terms with the intercept as well as the coefficients for the HDAX excess returns and the market factor. ${ }^{9}$

\footnotetext{
8 Additionally, our results are robust in applying the comprehensive German market factor provided by the AQR data library as market proxy in the 1-factor model. Note that the correlation of monthly total returns between HDAX and the German AQR market factor is about 0.99

9 A fully-integrated model with additional SMB, HML as well as WML interaction terms provide statistically and economically similar results.
}

Figure 4 plots the cumulative portfolio values for the HDAX (heavy dashed black line) as well as the ew betaneutral strategy (dashed black line) and the vw beta-neutral strategy (solid black line) over time. The portfolios start with an initial value of 1000 on March 31, 2003. The exploitation of the dividend month premium clearly adds value to the basic HDAX investment over 15 years up until December 2017. The ew strategy performs best over time. The final portfolio values range between 8310 for the vw strategy and 13,470 for the ew strategy-compared to the 5700 of the HDAX portfolio. In a next step, we consider risk and transaction costs in our analysis.

Table 4 provides the results for the HDAX as a benchmark index and for the beta-neutral strategies. Panel A shows performance and risk measures. The higher monthly mean returns $\left(\mu_{r}\right)$ of the beta-neutral strategies come with relatively low volatility of returns $\left(\sigma_{r}\right)$, resulting in significantly higher Sharpe Ratios (SR) compared to the HDAX.

\footnotetext{
${ }^{10}$ For the estimation of BETC, we consider every single-stock investment, purchase and liquidation within the investment period. We assume no further costs for the additional market investments nor for the EONIA investments.
} 


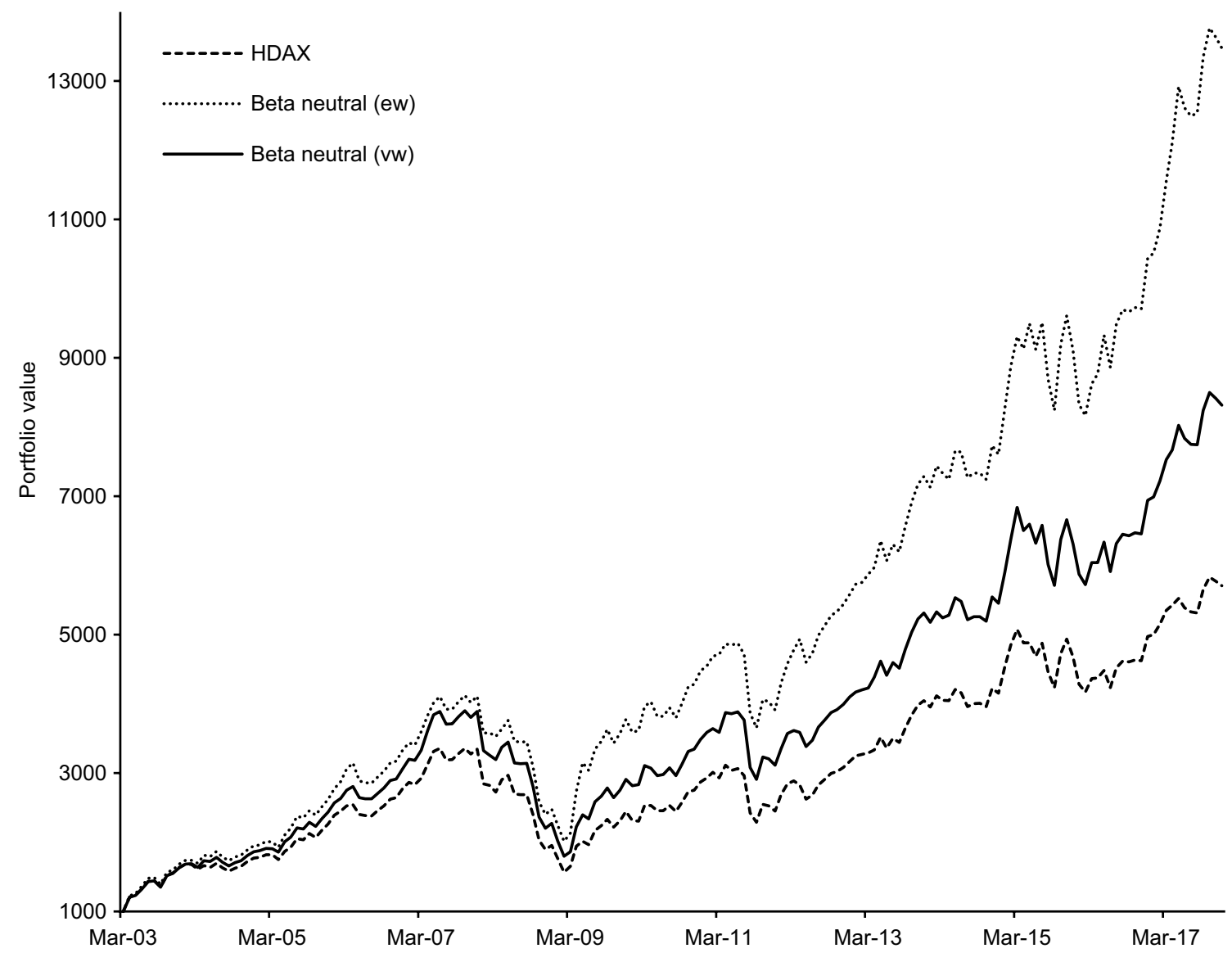

Fig. 4 Portfolio value over time. This figure plots the cumulative portfolio values for the HDAX (heavy dashed black line), the ew beta-neutral strategy (dashed black line) and the vw beta-neutral strategy (solid black line) over time. The portfolios start with an initial value of 1000 on March 31, 2003. The beta-neutral strategies extend a basic HDAX investment with additional investments in

The tracking error (TE) varies between $0.80 \%$ for the vw beta-neutral strategy and $1.61 \%$ for the ew beta-neutral strategy. On average, we additionally invest in 90 dividendpaying stocks a year, reflected by a relatively high turnover. The average yearly turnover (turnover) varies between $219.99 \%$ for the ew beta-neutral strategy and $260.67 \%$ for the vw beta-neutral strategy.

Panel B in Table 4 shows the OLS results for the 1-factor model as well as the information ratio (IR) and the oneway break-even transaction costs (BETC). We find a highly significant 1-factor alpha $\left(\alpha^{1 F}\right)$ for both strategies, varying between $0.22 \%$ for the vw beta-neutral strategy and $0.47 \%$ for the ew beta-neutral strategy per month. The IRs show a comparable pattern. The exploitation of the dividend month premium leads to a strong outperformance compared to the HDAX benchmark. The BETC further show that the outperformance of our beta-neutral strategies is quite robust. The BETC vary between 0.30 and $0.79 \%$, despite the relatively high turnover. In additional analyses, our exploitation of the dividend-paying stocks. The holding period of each investment in a dividend-paying stock starts at the end of the announcement-date and ends with the liquidation at the end of the ex-date. The ew approach applies equal weights, the vw approach applies value weights for the additional stock investments. The sample covers all trading days from April 2003 to December 2017. Data Source: Refinitiv EIKON

dividend month premium leads to similar results, even if we only consider the period after the publication of Hartzmark and Solomon (2013). Czaja et al. (2013) report that in institutional trading, one-way transaction costs range between single digits to $0.30 \%$ for German HDAX stocks. However, large-in-scale trades may lead to even higher transactions costs when taking into account a trade's market impact. Thus, the feasibility of our strategies depends on a stock's fungibility as well as portfolio managers' trading conditions.

Panel C in Table 4 presents the OLS results for the 4-factor model. We see a comparable performance of our betaneutral strategies in the monthly 4 -factor alphas $\left(\alpha^{4 F}\right)$. The $\alpha^{4 F}$ are higher in absolute terms because, among other reasons, the HDAX already shows a significant monthly $\alpha^{4 F}$ of $0.12 \%$. Our finding is in line with Cremers et al. (2012), who provide comparable evidence for passive benchmark indices in the US. Since the HDAX comprises stocks with rather large capitalization, the SMB exposure is, as expected, significant and negative. We also see a significant and negative 
Table 4 Performance and risk of HDAX and beta-neutral strategies

\begin{tabular}{|c|c|c|c|}
\hline & \multirow[t]{2}{*}{ HDAX } & \multicolumn{2}{|l|}{ Beta neutral } \\
\hline & & ew & $\mathrm{vw}$ \\
\hline \multicolumn{4}{|c|}{ Panel A: performance and risk } \\
\hline$\mu_{r}$ & 0.0113 & 0.0164 & 0.0134 \\
\hline$\sigma_{r}$ & 0.0525 & 0.0570 & 0.0531 \\
\hline SR & 0.1927 & $0.2673 * * *$ & $0.2314 * * *$ \\
\hline TE & 0 & 0.0161 & 0.0080 \\
\hline Turnover & - & 2.1999 & 2.6067 \\
\hline \multicolumn{4}{|c|}{ Panel B: 1-factor model } \\
\hline$\alpha^{1 F}$ & 0 & $\begin{array}{l}0.0047 * * * \\
(0.0013)\end{array}$ & $\begin{array}{l}0.0022 * * * \\
(0.0006)\end{array}$ \\
\hline$\beta^{\mathrm{HDAX}}$ & 1 & $\begin{array}{l}1.0415^{* * *} \\
(0.0407)\end{array}$ & $\begin{array}{l}1.0001 * * * \\
(0.0120)\end{array}$ \\
\hline IR & - & 0.2919 & 0.2750 \\
\hline BETC & - & 0.0079 & 0.0030 \\
\hline \multicolumn{4}{|c|}{ Panel C: 4-factor model } \\
\hline$\alpha^{4 F}$ & $\begin{array}{l}0.0012 * * \\
(0.0006)\end{array}$ & $\begin{array}{l}0.0073 * * * \\
(0.0020)\end{array}$ & $\begin{array}{l}0.0035 * * * \\
(0.0008)\end{array}$ \\
\hline$\beta^{\mathrm{Mkt}}$ & $\begin{array}{l}1.0899 * * * \\
(0.0164)\end{array}$ & $\begin{array}{l}1.1198 * * * \\
(0.0328)\end{array}$ & $\begin{array}{l}1.1008 * * * \\
(0.0194)\end{array}$ \\
\hline$\beta^{\mathrm{SMB}}$ & $\begin{array}{l}-0.0852 * * * \\
(0.0221)\end{array}$ & $\begin{array}{l}-0.0358 \\
(0.0413)\end{array}$ & $\begin{array}{l}-0.0646^{* *} \\
(0.0323)\end{array}$ \\
\hline$\beta^{\mathrm{HML}}$ & $\begin{array}{l}-0.0126 \\
(0.0368)\end{array}$ & $\begin{array}{l}-0.0619 \\
(0.0420)\end{array}$ & $\begin{array}{l}-0.0519 * \\
(0.0283)\end{array}$ \\
\hline$\beta^{\mathrm{WML}}$ & $\begin{array}{l}-0.0722^{* * * *} \\
(0.0170)\end{array}$ & $\begin{array}{l}-0.1507 * * \\
(0.0696)\end{array}$ & $\begin{array}{l}-0.0752 * * * \\
(0.0256)\end{array}$ \\
\hline
\end{tabular}

This table shows our results for the HDAX index and our beta-neutral strategies. The beta-neutral strategies extend a basic HDAX investment with additional investments in dividend-paying stocks. The holding period of each investment in a dividend-paying stock starts at the end of the announcement-date and ends with the liquidation at the end of the ex-date. The ew approach applies equal weights, the vw approach applies value weights for the additional stock investment. The sample covers all trading days from April 2003 to December 2017. Panel A shows the mean monthly return $\left(\mu_{r}\right)$, volatility of portfolio returns $\left(\sigma_{r}\right)$, Sharpe Ratio (SR), tracking error (TE) and the yearly average turnover (Turnover). We apply $t$-statistics by Memmel (2003) to test differences between the strategies' Sharpe Ratios and the Sharpe Ratio of the HDAX. Panel B provides the OLS estimates for the 1-factor model as well as the information ratio (IR) and one-way break-even transaction costs (BETC) turning the $\alpha^{1 F}$ insignificant at the $10 \%$ level. Panel C shows the OLS estimates for the 4-factor model. Standard errors in Panel B and C are presented in parentheses and are adjusted following Newey and West (1987). *,**, and *** indicate statistical significance at the $10 \%, 5 \%$ and $1 \%$ level, respectively. Data source: Refinitiv EIKON exposure on WML. The vw beta-neutral strategy shows similar factor exposures. With the ew beta-neutral strategy, the exposure on SMB becomes insignificant, since the equal weight approach applies disproportionate weights for the additional investments in dividend-paying stocks.

In the following, we take into account the cluster of dividend payments in the second quarter of a year. Table 5 provides the results. Panel A shows the coefficients for the 1 -factor model (Eq. (7)). For both strategies, $\theta^{1 F}$ is significantly different from zero and varies between $0.50 \%$ for the vw beta-neutral strategy and $0.84 \%$ for the ew beta-neutral strategy. This result is as expected. It indicates that our betaneutral strategies exploiting the dividend month premium show significantly higher abnormal returns $\left(\alpha^{1 F}+\theta^{1 F}\right)$ in the second quarter of a year. The insignificant $\omega^{\mathrm{HDAX}}$ provide evidence that neither strategy leads to significantly different HDAX exposures in the second quarter.

Panel B in Table 5 presents the results for the 4 -factor model (Eq. (8)). We see almost identical results for $\theta^{4 F}$ in the 4-factor model specification, indicating a higher outperformance in the second quarter compared to the remaining quarters. The level of the abnormal return $\left(\alpha^{4 F}+\theta^{4 F}\right)$ in the second quarter, compared to our results of the 1 -factor model, is consistent with our findings in Table 4.

In a final step, we show a possible enhancement of our beta-neutral strategies to improve their feasibility. When it comes to implementing investment strategies, portfolio managers may have individual needs. In addition to the obvious 
Table 5 Market exposures and alphas of beta-neutral strategies in the second quarter

\begin{tabular}{lll}
\hline & \multicolumn{2}{l}{ Beta neutral } \\
\cline { 2 - 3 } & ew & vw \\
\hline Panel A: 1-factor model & & \\
$\alpha^{1 F}$ & $0.0025^{* * *}$ & 0.0009 \\
& $(0.0007)$ & $(0.0006)$ \\
$\theta^{1 F}$ & $0.0084 * *$ & $0.0050^{* * *}$ \\
& $(0.0038)$ & $(0.0016)$ \\
$\beta^{\mathrm{HDAX}}$ & $0.9940^{* * *}$ & $0.9894 * * *$ \\
& $(0.0139)$ & $(0.0100)$ \\
$\omega^{\mathrm{HDAX}}$ & 0.1674 & 0.0358 \\
& $(0.1154)$ & $(0.0266)$ \\
Panel B: 4-factor model & & \\
$\alpha^{4 F}$ & $0.0046^{* * *}$ & $0.0020^{* * *}$ \\
& $(0.0011)$ & $(0.0008)$ \\
$\theta^{4 F}$ & $0.0083^{* *}$ & $0.0051^{* * *}$ \\
& $(0.0035)$ & $(0.0019)$ \\
$\beta^{\mathrm{Mkt}}$ & $1.0847 * * *$ & $1.0876^{* * *}$ \\
& $(0.0310)$ & $(0.0193)$ \\
$\omega^{\mathrm{Mkt}}$ & $0.2120^{*}$ & $0.0834 *$ \\
& $(0.1169)$ & $(0.0469)$ \\
\hline
\end{tabular}

This table shows the results for our beta-neutral strategies. The beta-neutral strategies extend a basic HDAX investment with additional investments in dividend-paying stocks. The holding period of each investment in a dividend-paying stock starts at the end of the announcement-date and ends with the liquidation at the end of the ex-date. The ew approach applies equal weights, the vw approach applies value weights for the additional stock investment. The sample covers all trading days from April 2003 to December 2017. Panel A shows the OLS estimates for the 1-factor model following equation (7). For the second quarter of a year, $\theta^{1 F}$ represents the additional intercept and $\omega^{H D A X}$ the additional HDAX exposure of our betaneutral strategies. Panel B shows the OLS estimates for the 4-factor model following equation (8). For the second quarter of a year, $\theta^{4 F}$ represents the additional intercept and $\omega^{M k t}$ the additional market exposure of our beta-neutral strategies. Standard errors are presented in parentheses. All standard errors are adjusted following Newey and West (1987). *,** and *** indicate statistical significance at the $10 \%$, $5 \%$ and $1 \%$ level, respectively. Data source: Refinitiv EIKON

issue of scalability, there are often tracking error restrictions. In Section Abnormal returns around ex-dates and announcement-dates, we showed that post-announcement drifts are especially strong for German stocks with positive dividend surprise. Therefore, we now apply our beta-neutral strategies to stocks with positive dividend surprise in order to select those with the strongest drift while decreasing tracking error as well as turnover. With the implementation of our enhanced beta-neutral strategies, we only consider about 25 stocks with positive dividend surprise a year. ${ }^{11}$

Panel A in Table 6 presents the performance and risk measures. Since we consistently apply the same weighting

\footnotetext{
11 Figure 6 in the appendix plots the cumulative portfolio values for the HDAX and the beta-neutral strategies.
}

Table 6 Beta-neutral strategies with positive dividend surprise

\begin{tabular}{lll}
\hline & \multicolumn{2}{l}{ Beta neutral } \\
\cline { 2 - 3 } & ew & vw \\
\hline $\begin{array}{l}\text { Panel A: performance } \\
\text { and risk }\end{array}$ & \\
$\mu_{r}$ & 0.0140 & 0.0125 \\
$\sigma_{r}$ & 0.0533 & 0.0523 \\
SR & $0.2407 * * *$ & $0.2175^{* * *}$ \\
TE & 0.0073 & 0.0045 \\
Turnover & 0.6473 & 0.6019 \\
Panel B: 1- and 4-factor & & \\
$\quad$ model & & \\
$\alpha^{1 F}$ & $0.0027 * * *$ & $0.0013 * * *$ \\
& $(0.0006)$ & $(0.0003)$ \\
$\alpha^{4 F}$ & $0.0042^{* * *}$ & $0.0026 * * *$ \\
& $(0.0010)$ & $(0.0007)$ \\
IR & 0.3699 & 0.2889 \\
BETC & 0.0176 & 0.0093 \\
\hline
\end{tabular}

This table shows the results for our beta-neutral strategies. The beta-neutral strategies extend a basic HDAX investment with additional investments in dividend-paying stocks. The holding period of each investment in a dividend-paying stock starts at the end of the announcement-date and ends with the liquidation at the end of the ex-date. The ew approach applies equal weights, the vw approach applies value weights for the additional stock investment. The sample covers all stocks with positive dividend surprise. The difference between a corporation's actual dividend announcement and the mean I/B/E/S_estimate for the respective dividend payment defines the dividend surprise. We use the mean I/B/E/S_estimate available one day in advance of the announcement-date. It is positive news if the difference is larger than 5\%. All trading days from April 2003 to December 2017 are considered. Panel A shows the mean monthly return $\left(\mu_{r}\right)$, volatility of portfolio returns $\left(\sigma_{r}\right)$, Sharpe Ratio (SR), tracking error (TE) and the yearly average turnover (Turnover). We apply $t$-statistics by Memmel (2003) to test differences between the strategies' Sharpe Ratios and the Sharpe Ratio of the HDAX. Panel B provides the OLS estimates for the 1- and 4-factor model as well as the information ratio (IR) and one-way break-even transaction costs (BETC) turning the $\alpha^{1 F}$ insignificant at the $10 \%$ level. Standard errors in Panel B and C are presented in parentheses and are adjusted following Newey and West (1987).*,**, and *** indicate statistical significance at the $10 \%, 5 \%$ and $1 \%$ level, respectively. Data source: Refinitiv EIKON

as for the full sample, we invest less frequently in additional dividend-paying stocks. This results in decreasing measures, most notably in a lower turnover as well as lower TE. The TE varies between $0.45 \%$ for the vw strategy and $0.73 \%$ for the ew strategy.

Panel B in Table 6 provides the OLS estimates of the $\alpha^{1 F}$ and $\alpha^{4 F}$, as well as the IR and the BETC. The considerably lower TEs lead to higher IRs of $28.89 \%$ and $36.99 \%$, respectively, compared to the full sample results in Table 4. The BETC are also clearly higher and vary between 0.93 and $1.76 \%$. Thus, large-in-scale trades with probably higher trading costs can be implemented more easily with these 
enhanced beta-neutral strategies. The higher BETC of our enhanced strategies might be caused by a lower turnover of the respective strategies and by a higher $\alpha^{1 F}$ earned by each additional single-stock investment. The comparison is somewhat difficult, since we compare two different sample sizes and, thus, quantities of additional single-stock investments per year. Applying the IR tackles the problem, setting the $\alpha^{1 F}$ in relation to the TE. Eventually, exploiting the dividend month premium, our enhanced beta-neutral strategies show higher IRs as well as higher BETC. This indicates that the beta-neutral strategies for our sub sample of stocks with positive dividend surprise produce a higher performance and are more robust to varying trading costs.

\section{Conclusions}

In our paper, we provide evidence for the existence and the exploitability of a dividend month premium in German stocks. Introduced by Hartzmark and Solomon (2013) for US stocks, the dividend month premium describes abnormal returns in months of predicted dividend payments. Positive abnormal returns in the period between announcement-date and the ex-dividend date are the main driver for the dividend month premium. This premium is most consistent with the price pressure from dividend-seeking investors. Potential explanations for dividend demand are catering reasons (see, e.g., Baker and Wurgler 2004), investors ignoring the fall in stock prices from cum-dividend date to ex-dividend date (Hartzmark and Solomon 2019), or mutual funds investing in dividend-paying stocks in advance of ex-dates to increase their dividend yield (Harris et al. 2015).

In our event study of German stocks between 2003 and 2017, we find a robust and significant cumulative abnormal return of $1.79 \%$ over the 45 days prior to the ex-dividend date. We further take into account dividend surprises and provide evidence that the cumulative abnormal return is particularly high for stocks with positive dividend news.

In the second part of our paper, we study the practical relevance of the dividend month premium in portfolio management. Knowing the dates of dividend announcements and payments enable portfolio managers to exploit the dividend month premium. We apply beta-neutral strategies, extending a basic market investment with additional investments in dividend-paying stocks. In doing so, on the day of the singlestock investment, we keep the systematic risk of the underlying portfolio unchanged at one. Our beta-neutral strategies lead to significant monthly 1 -factor alphas between 0.13 and $0.47 \%$. One-way break-even transaction costs, removing the statistical significance of the 1-factor alpha at the $10 \%$ level, range from 0.30 to $1.76 \%$. Our results are robust across various strategy specifications, and the exploitation of the dividend month premium is still profitable in the period after the publication of Hartzmark and Solomon (2013).

\section{Appendix}

\section{See Figures 5 and 6.}

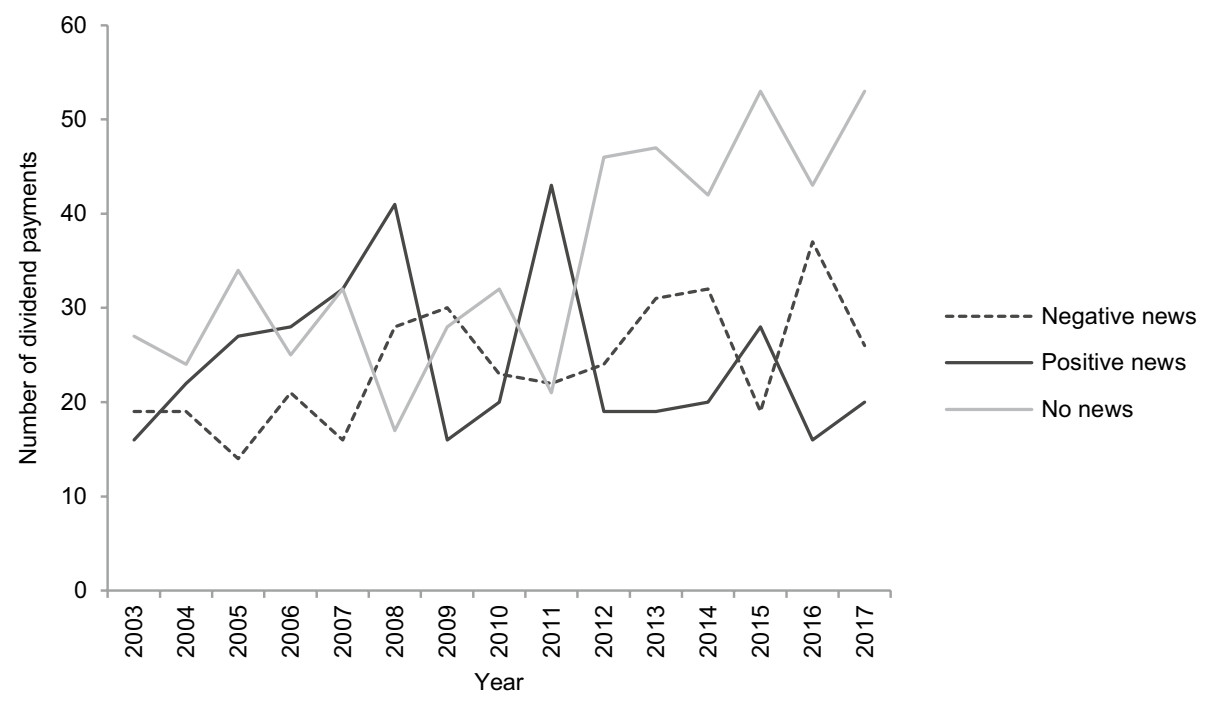

Fig. 5 Dividend surprises over time. This figure illustrates the distribution of dividend payments with negative news (dashed black line), positive news (solid black line) and no news (solid gray line) between March 2003 and December 2017. The difference between a corporation's actual dividend announcement and the mean I/B/E/S_estimate for the respective dividend payment defines the dividend surprise. We use the mean I/B/E/S_estimate available one day in advance of the announcement-date. It is positive (negative) news if the difference is larger (smaller) than 5\% (-5\%). The data sample covers 1252 dividend payments. Data source: Refinitiv EIKON 


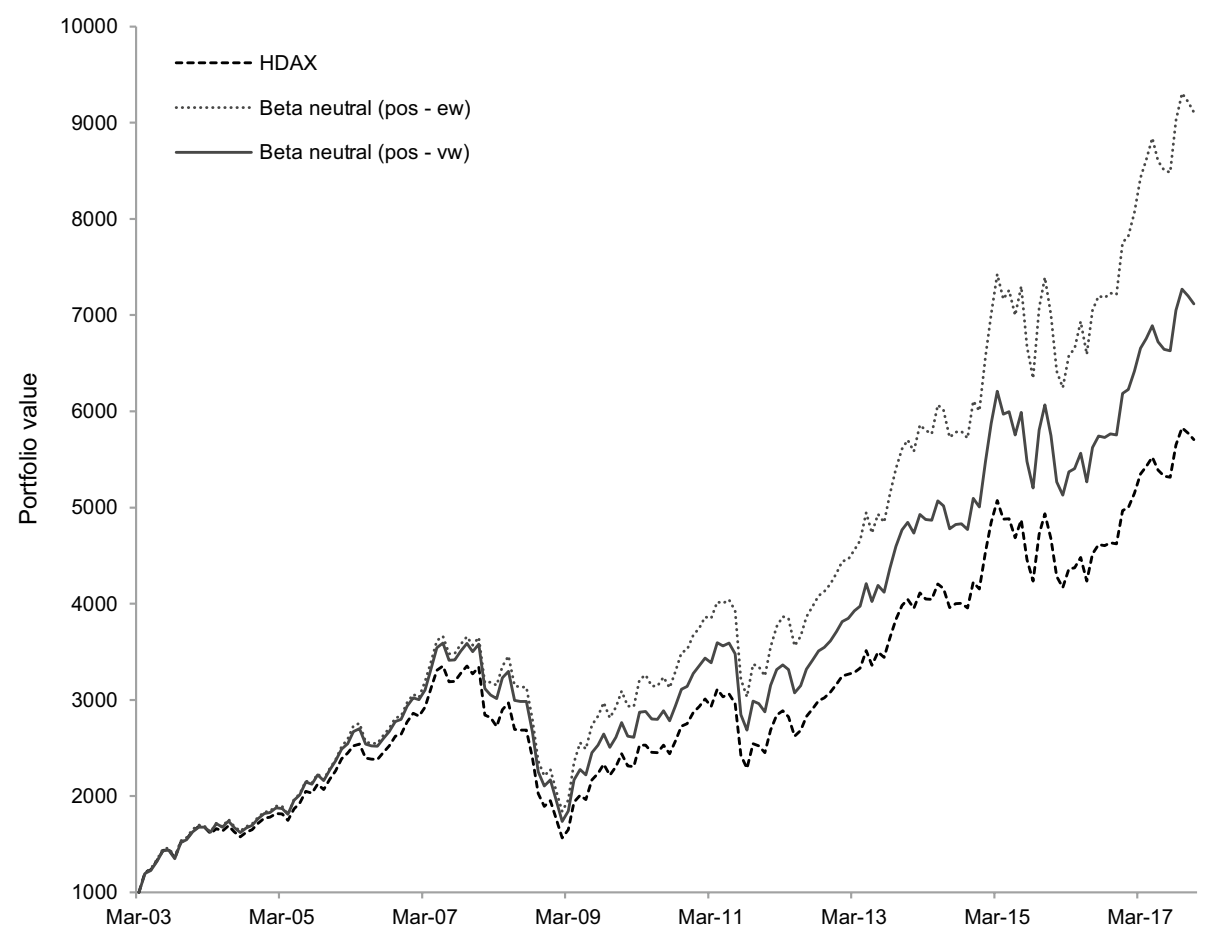

Fig. 6 Portfolio value over time - Stocks with positive dividend surprises. This figure plots the cumulative portfolio values for the HDAX (heavy dashed black line), the ew beta-neutral strategy (dashed black line) and the vw beta-neutral strategy (solid black line) over time. The portfolios start with an initial value of 1000 on March 31, 2003. The beta-neutral strategies extend a basic HDAX investment with additional investments in dividend-paying stocks. The holding period of each investment in a dividend-paying stock starts at the end of the announcement-date and ends with the liquidation at the end of the ex-date. The ew approach applies equal weights, the vw approach applies value weights for the additional stock investments. The sample covers all stocks with positive dividend surprise. The difference between a corporation's actual dividend announcement and the mean $\mathrm{I} / \mathrm{B} / \mathrm{E} / \mathrm{S}$ _estimate for the respective dividend payment defines the dividend surprise. We use the mean I/B/E/S_estimate available one day in advance of the announcement-date. It is positive news if the difference is larger than 5\%. All trading days from April 2003 to December 2017 are considered. Data Source: Refinitiv EIKON 
Acknowledgements We are grateful for helpful comments and suggestions from the editor, the anonymous referee, Jenifer Anthonisamy, Christine Crozier, Hannah Lea Huehn, Martin Rohleder, Martin Wallmeier and seminar participants at the International Ph.D. Seminar 2019 in Bayreuth.

Funding Open Access funding enabled and organized by Projekt DEAL.

Open Access This article is licensed under a Creative Commons Attribution 4.0 International License, which permits use, sharing, adaptation, distribution and reproduction in any medium or format, as long as you give appropriate credit to the original author(s) and the source, provide a link to the Creative Commons licence, and indicate if changes were made. The images or other third party material in this article are included in the article's Creative Commons licence, unless indicated otherwise in a credit line to the material. If material is not included in the article's Creative Commons licence and your intended use is not permitted by statutory regulation or exceeds the permitted use, you will need to obtain permission directly from the copyright holder. To view a copy of this licence, visit http://creativecommons.org/licenses/by/4.0/.

\section{References}

Ainsworth, A., Nicholson, M., 2015. Can dividend schedules predict abnormal returns? International evidence. Working paper, University of Sydney.

Andres, C., A. Betzer, I. Van den Bongard, C. Haesner, and E. Theissen. 2013. The information content of dividend surprises: Evidence from Germany. Journal of Business Finance and Accounting 40: 620-645.

Baker, M., and J. Wurgler. 2004. A catering theory of dividends. Journal of Finance 59: 1125-1165.

Battalio, R., and R. Mendenhall. 2005. Earnings expectations, investor trade size, and anomalous returns around earnings announcements. Journal of Financial Economics 77: 289-319.

Buettner, T., C. Holzmann, F. Kreidl, and H. Scholz. 2020. Withholding-tax non-compliance: the case of cum-ex stock-market transactions. International Tax and Public Finance 27: 1425-1452.

Carhart, M.M. 1997. On persistence in mutual fund performance. Journal of Finance 52: 57-82.

Cremers, M., A. Petajisto, and E. Zitzewitz. 2012. Should benchmark indices have alpha? Revisiting performance evaluation. Critical Finance Review 2: 1-48.

Czaja, M., P. Kaufmann, and H. Scholz. 2013. Enhancing the profitability of earnings momentum strategies: The role of price momentum, information diffusion and earnings uncertainty. Journal of Investment Strategies 2 (4): 3-57.

Dimson, E. 1979. Risk measurement when shares are subject to infrequent trading. Journal of Financial Economics 7: 197-226.

Flammer, C. 2013. Corporate social responsibility and shareholder reaction: the environmental awareness of investors. Academy of Management Journal 56: 758-781.

Glück, M., B. Hübel, and H. Scholz. 2021. Currency conversion of fama-french factors: how and why. Journal of Portfolio Management, Quantitative Special Issue 47 (2): 157-175.

Grundy, B.D., and J.S. Martin. 2001. Understanding the nature of the risks and the source of the rewards to momentum investing. Review of Financial Studies 14: 29-78.
Haesner, C., and D. Schanz. 2013. Payout policy tax clienteles, exdividend day stock prices and trading behavior in Germany: The case of the 2001 tax reform. Journal of Business Finance and Accounting 40: 527-563.

Harris, L.E., S.M. Hartzmark, and D.H. Solomon. 2015. Juicing the dividend yield: Mutual funds and the demand for dividends. Journal of Financial Economics 116: 433-451.

Hartzmark, S.M., and D.H. Solomon. 2013. The dividend month premium. Journal of Financial Economics 109: 640-660.

Hartzmark, S.M., and D.H. Solomon. 2018. Recurring firm events and predictable returns: The within-firm time series. Annual Review of Financial Economics 10: 499-517.

Hartzmark, S.M., and D.H. Solomon. 2019. The dividend disconnect. Journal of Finance 74: 2153-2199.

Jensen, M.C. 1968. The performance of mutual funds in the period 1945-1964. Journal of Finance 23: 389-416.

Kolari, J.W., and S. Pynnönen. 2010. Event study testing with crosssectional correlation of abnormal returns. Review of Financial Studies 23: 3996-4025.

Krueger, P. 2015. Corporate goodness and shareholder wealth. Journal of Financial Economics 115: 304-329.

Lakonishok, J., and T. Vermaelen. 1986. Tax-induced trading around ex-dividend days. Journal of Financial Economics 16: 287-319.

MacKinlay, C.A. 1997. Event studies in economics and finance. Journal of Economic Literature 35: 13-39.

Memmel, C. 2003. Performance hypothesis testing with the Sharpe Ratio. Finance Letters 2003: 21-23.

Newey, W.K., and K.D. West. 1987. A simple, positive semi-definite, heteroskedasticity and autocorrelation consistent covariance matrix. Econometrica 55: 703-708.

Roll, R. 1992. A mean variance analysis of tracking error. Journal of Portfolio Management 18: 13-22.

Sharpe, W.F. 1994. The Sharpe Ratio. Journal of Portfolio Management 21: 49-58.

Spengel, C., 2016. Sachverständigengutachten nach §28 PUAG für den 4. Untersuchungsausschuss der 18. Wahlperiode. https://www. bundestag.de/blob/438666/15d27facf097da2d56213e8a09e270 08/sv2_spengel-data.pdf. Last accessed on August 2nd, 2018.

Treynor, J.L., and F. Black. 1973. How to use security analysis to improve portfolio selection. Journal of Business 46: 66-86.

Publisher's Note Springer Nature remains neutral with regard to jurisdictional claims in published maps and institutional affiliations.

Felix Kreidl is research assistant at the Chair of Finance and Banking, Friedrich-Alexander-Universität Erlangen-Nürnberg, Germany. He holds a B.A. in Business Administration and Economics from the Friedrich-Alexander-Universität Erlangen-Nürnberg and a M.Sc. in Finance with Banking from the University of Bath, UK. He received a Ph.D. in Finance from Friedrich-Alexander-Universität Erlangen-Nürnberg.

Hendrik Scholz is Professor of Finance and Banking and holder of the Chair of Finance and Banking at the Friedrich-Alexander-Universität Erlangen-Nürnberg, Germany. He graduated in business administration from the University of Göttingen, Germany, where he also finished his Ph.D. Afterward, he received his habilitation at the Catholic University of Eichstätt-Ingolstadt, Germany. His research focuses on asset management, mutual funds, sustainable finance, bank management and structured financial products. 